\title{
MORPHOLOGICAL EVOLUTION OF THE DEE ESTUARY, EASTERN IRISH SEA, UK: A TIDAL ASYMMETRY APPROACH
}

\author{
Rowena Moore ${ }^{* a, b}$, Judith Wolf ${ }^{b}$, Alejandro Souza ${ }^{b}$, Stephen Flint ${ }^{a}$ \\ ${ }^{a}$ University of Liverpool \\ Department of Earth and Ocean Sciences \\ 4 Brownlow Street \\ Liverpool \\ L69 3GP \\ UK \\ ${ }^{\text {b} P r o u d m a n ~ O c e a n o g r a p h i c ~ L a b o r a t o r y ~}$ \\ Joseph Proudman Building \\ 6 Brownlow Street \\ Liverpool \\ L3 5DA \\ UK \\ *r.d.moore@liv.ac.uk \\ Tel: (+44) 01517945256 \\ Fax: (+44) 01517954801
}

\begin{abstract}
Asymmetry in the tide (unequal ebb and flood duration) is a dominant factor in causing residual sediment transport and morphological changes in estuaries. The evolution of estuarine morphology is a process of dynamic equilibrium in the short term, while these features are ephemeral in the long-term. In this study we investigate the spatial distribution of tidal distortion and asymmetry of the Dee estuary, UK, by 3dimensional numerical modelling methods. High resolution LIDAR surveys are used to underpin and explain our numerical modelling results in terms of basin hypsometry and areas of recent erosion and deposition. Harmonic analysis of the numerical modelling results showed that the shallower intertidal areas (sand and mud banks) were the most tidally asymmetric, showing flood dominance. The main navigation channels showed some ebb dominance but the tides here were relatively undistorted. This overall flood dominance is likely to induce net sediment import to the Dee, which explains known historical morphological changes (large scale accretion over the last 2 centuries) and also recent morphological changes as seen from the LIDAR surveys (which show predominantly net accretion between 2003 and 2006). Hypsometrical analysis suggests the Dee may be approaching equilibrium, and that the flood dominance and sedimentation rate may therefore decrease in the future. In an infilling estuary, an increase in the area and elevation of tidal flats can eventually shift an estuary towards ebb dominance, as shown by previous research and by 'idealised estuary' modelling results presented in this study. The large tidal amplitude to hydraulic depth ratio of the Dee, however, suggests that the tidal flats would have to be very extensive indeed for this to occur.
\end{abstract}




\section{Keywords : morphology, estuaries, tidal asymmetry, sediment transport, hydrodynamics}

\section{Introduction and Objectives}

Estuaries and tidal bays are complex dynamic systems subject to marine and terrestrial influences. They are commonly of high recreational, commercial and ecological value and as such their management is of great importance. Integral to coastal management is the need for an in-depth knowledge of estuarine morphological processes and evolution, in order to predict changing patterns of sediment deposition and removal.

The purpose of this study is to investigate the morphodynamic processes and identify the mechanisms which have led to the present day bathymetry of the Dee estuary, in order to predict future changes. Data from recent LIDAR surveys are presented and used in a hypsometrical analysis in order to infer basin-scale behavioural trends. The concepts of estuarine equilibrium and stability in relation to the Dee are then discussed. The tidal propagation in the Dee is described and results from a numerical modelling analysis presented. The symmetry of the tides in the Dee and the pattern of residual currents and residual sediment transport are investigated. Finally, using idealised estuary modelling concepts, the sensitivity of ebb or flood dominance to changes in hypsometry (such as changing channel depths and tidal flat elevations) is explored.

Estuarine morphology is controlled by a combination of hydrodynamical conditions, the sedimentary environment and sediment supply and the underlying geology. The morphological evolution of tidal basins, specifically, is the result of continuous interaction between the sedimentary environment and non-linear tidal propagation (Dronkers, 1998). Such interactions can result in residual circulations and spatial variation in sediment flux (convergence and divergence, leading to net accretion or erosion). Furthermore, feedback from morphological change affects the hydrodynamic tidal regime and sediment movement, particularly changes to the mean depth of the estuary and changes in the elevation/volume of inter-tidal areas. Feedback mechanisms and non-linear interactions have made morphological evolution of tidal basins a complex phenomenon to predict. Also, although tidal propagation is widely accepted as the major bathymetric forcing mechanism in estuaries, recent theory suggests that it is the bathymetry that controls the sediment regime, and not the reverse as previously thought (Prandle et al., 2006). In either case, undoubtedly morphodynamics and hydrodynamics are tightly coupled in longterm evolutionary processes (Lanzoni and Seminara, 2002).

In recent years significant advances have been made in morphological modelling, in which several approaches exist. Firstly process-based or 'bottom-up' models use dynamical equations of physical processes in separate modules for flow field and sediment transport (for example, Lesser et al., 2004, Wang et al., 1995, and the various models described in Nicholson et al., 1997). Conversely, 'top-down' models use basin scale morphological behaviour such as analysing geometrical relationships to predict changes. Examples of this include regime relationships like the tidal prism relationships of O'Brien (1939) and Eyesink (1991), form analysis (Prandle and Rahman, 1980) and tidal asymmetry analysis (Dronkers, 1986; Friedrichs and 
Aubrey, 1988). A mixture of these two approaches is seen in semi-empirical or 'hybrid' models which combine the complex 'bottom-up' method for simulating hydrodynamics, but use empirical formulae to simulate morphological changes (for example, van Dongeren and de Vriend, 1994). However, the accuracy of hydrodynamical simulations is far greater than that for modelling sediment erosion, transport and deposition (Prandle, 2004). Hence, rather than focussing on numerically modelled sediment transport this study will employ process-based hydrodynamical modelling, from which morphological change will be inferred.

\section{Tidal asymmetry}

A symmetrical tide is one where the rise and fall of the tide (flood and ebb) are of equal duration, with roughly equal maximum velocities attained, resulting in no net overall sediment transport. When the ebb and flood durations are unequal, this is known as tidal asymmetry and is caused by tidal wave distortion during propagation into shoaling water, along the coastal shelf and on entry into estuaries (Dronkers, 1986). The mechanism by which this occurs is the non-linear effect of tidal propagation. The principal sources of non-linearity are quadratic friction, timevarying water depth and time-varying cross-section width (i.e. friction, convergence and continuity, Friedrichs and Madsen, 1992).. As the tidal wave approaches the coast, it is travelling as a shallow water wave (with phase speed proportional to the square root of the water depth) and the crest travels faster than the trough due to the greater water depth beneath the peak. Ultimately, in extreme cases with large tidal ranges and a strongly converging basin, it is possible for the tidal wave to steepen until the crest catches up with the trough, whereby a tidal bore is formed, the same fundamental principle behind waves breaking on a beach (Pugh, 2004).

Tidal distortion (asymmetry) can be represented by harmonics of the astronomical tidal constituents (Speer and Aubrey, 1985). Higher tidal harmonics of the fundamental tidal periodicities are created by non-linear tidal propagation (Pingree and Griffiths, 1979). Assessing the level of tidal asymmetry has previously been investigated by means of estuary form analysis (Dronkers, 1998) and by means of tidal analysis comparing the $\mathrm{M}_{2}$ and $\mathrm{M}_{4}$ tidal constituents (Friedrichs and Aubrey, 1988). The $\mathrm{M}_{2}$ constituent is the dominant lunar semi-diurnal tidal constituent ( $\mathrm{M}$ for moon, subscript 2 for twice daily in frequency) and the $\mathrm{M}_{4}$ constituent is a quarterdiurnal non-linear harmonic overtide of $\mathrm{M}_{2}$. The overall effect of tidal asymmetry on morphology has been considered in some detail in Wang et al., 2002.

If the ebb duration is longer than the flood, continuity arguments state that there should be a shorter, more intense (higher velocity) flood flow (Aubrey and Speer, 1985). Higher flood velocities result in increased shear at the sea bed during the flood compared to the ebb. Once the threshold bed shear stress has been exceeded (that which is necessary for the initiation of sediment motion) any further increase can result in greater sediment resuspension. The sediment transport, therefore, is a function of the shear stress at a given time and the duration of the flow in which the threshold shear stress is exceeded. Ultimately this creates net sediment transport over a tidal cycle, with flood-dominated currents resulting in net sediment transport into the basin/estuary (van Dongeren and de Vriend, 1994). This may then cause basin infilling. Under ebb-dominant conditions, the opposite is true and net seaward transport will occur (Lanzoni and Seminara, 2002), causing sediment export from the estuary. The suspended load fraction of sediment transport is affected to a greater 
extent by tidal asymmetry than is the bedload fraction (Dronkers, 1986). Hence, the effect is likely to be greatest where small grain sizes dominate and suspension is the dominant transport method. This would include many estuaries, such as the Dee, where fine sand and silt dominate (generally non-cohesive). Also worthy of consideration is the river flow which is likely to increase flood currents and reduce the ebb currents in the deepest parts of the channels near the sea bed due to the imposed density differences (Dronkers, 1986). This strengthening or weakening of the gravitational circulation (when river flow is high or low respectively) may cause significant changes in tidal asymmetry even in macrotidal well-mixed estuaries.

Tidal asymmetry is often the dominant factor in causing net sediment transport and deposition, resulting in sediment trapping in coastal areas and estuaries (Castaing and Allen, 1981). Both the navigability of the estuarine channels and geological evolution of estuaries are affected by tidal asymmetry (Aubrey and Speer, 1985). Tidal asymmetry is, therefore, a controlling factor for morphological development in tidal basins (Wang et al., 2002). Consequently, it is of paramount importance when studying the sediment dynamics of an estuary to understand the nature of the tidal propagation therein.

\section{Morphological equilibrium and stability}

The concept of estuarine equilibrium theorises that, under a given set of hydrodynamical conditions, there will be an equilibrium morphology which the estuary will evolve to attain, and then become stable (static bathymetry). Morphodynamic equilibrium requires that the long term average sediment flux through an inlet/estuary should equate to zero (e.g. Dronkers 1986; 1998). Incidentally, an estuary with an equilibrium configuration may still retain a degree of tidal asymmetry (Lanzoni and Seminara, 2002).

Morphological stability is the ability of an estuary to return to its original state after a disturbance (Hume and Herdendorf, 1993). If a system is morphologically stable, a perturbation of morphology should produce an alteration of the tidal propagation, causing an unbalancing of the ebb and flood sediment fluxes, in order to restore the system to its original situation (Dronkers, 1998). However, since external conditions such as mean sea level and wind wave patterns (or indeed human interference) do not remain static over time, it is difficult to say whether a fully stable estuary can exist (Dronkers, 1986). The tidal inlet or estuary may continuously be adapting to a new equilibrium (van Dongeren and de Vriend, 1994). Hence, it may be that a kind of dynamic morphological equilibrium and stability exist instead. Having some form of equilibrium may be regarded as a necessary condition in order for an estuary to actually exist and persist in the long term. An unbalanced estuary (unstable, without equilibrium status) is likely to erode away or, more likely, infill completely, eventually becoming part of the rock record.

\section{Dee estuary: Background and database}

The Dee is a macrotidal, funnel-shaped estuary situated in the eastern Irish Sea between England and Wales (Fig 1). It is a coastal plain estuary, formed during the transgression and drowning of a valley cut by the Dee river during sea level lowstand. The natural estuary extended as far inland as the Roman city of Chester (2000 years BP), giving a length of $35-40 \mathrm{~km}$. Canalisation of the river at the head of the estuary 
(the 'New Cut' in the $18^{\text {th }}$ century), and associated land drainage and reclamation, drastically altered the hydrodynamical regime and reduced the estuary length to $30 \mathrm{~km}$. Previously the main navigation channel was located close to the eastern (English) shore of the estuary. Canalisation forced a shift in the channel close to the western (Welsh) shore. This caused heavy siltation and accretion on the eastern shore due to the ensuing low current conditions. The high level of accretion led to the estuary becoming a very shallow system, and as the mudbanks and sandbanks increased in elevation, vast areas became colonised by saltmarsh, pioneered initially by Salicornia and then dominated by Spartina townsendii (Marker, 1967). The introduction of Spartina anglica in the 1930s is thought to have significantly accelerated the spreading of the saltmarsh area (Hutchinson and Prandle, 1994).

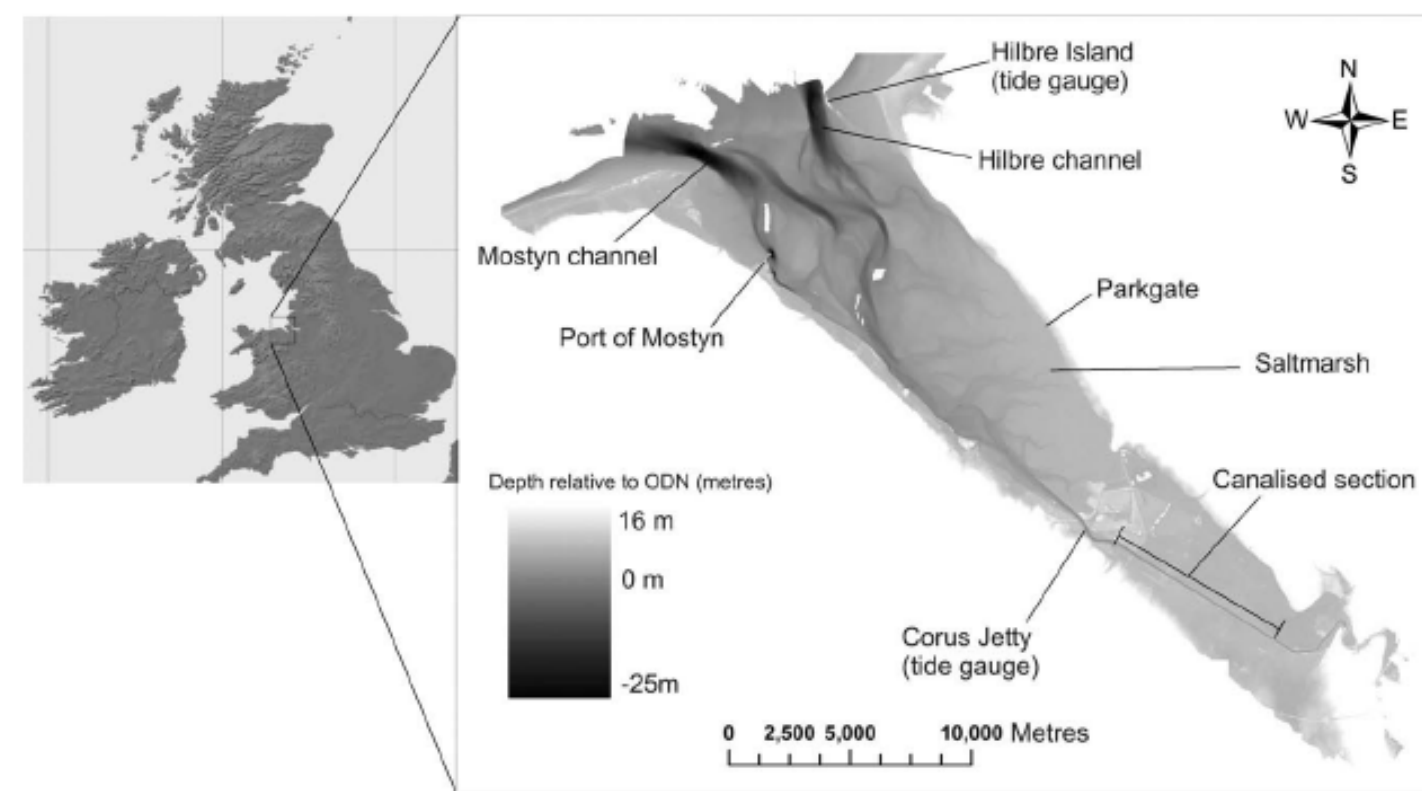

Figure 1. The location and setting of the Dee estuary, eastern Irish Sea, UK. The bathymetry is shown from a LIDAR survey of 2003

This saltmarsh-induced land reclamation led to a reduction of the effective estuary length, further exacerbated by the construction of a training wall extending the canalised section of the Dee river (designed to promote navigability). The presence of large tides and associated strong tidal currents make the Dee a very high energy, dynamic system. The average tidal prism in the Dee is $4 \times 10^{8} \mathrm{~m}^{3}$, representing a volumetric increase of over $80 \%$ between mean low water and mean high water. Mean river discharge is comparatively small, in the order of $31 \mathrm{~m}^{3} \mathrm{~s}^{-1}$ (data from the UK National River Flow Archive from a gauging station run by the Environment Agency on the river Dee at Manley Hall). A tide-dominated estuary will typically have a river discharge at least an order of magnitude smaller than the tidal prism (Lanzoni and Seminara, 2002). This is certainly the case in the Dee, as the river discharge equates to around $0.35 \%$ of the tidal prism over a tidal cycle. The mean spring tidal range at Hilbre Island near the mouth of the eastuary is $7-8 \mathrm{~m}$.

The modern-day Dee estuary has an effective length of $30 \mathrm{~km}$, with a maximum width of $8.5 \mathrm{~km}$ at the estuary mouth. The main conveyance channel bifurcates $12 \mathrm{~km}$ seaward from the canalised river at the head of the estuary, resulting in two deep channels extending into Liverpool Bay (called Mostyn Channel to the west and Hilbre 
Channel to the east). A good synopsis of the history of siltation and saltmarsh expansion in the Dee can be found in Marker (1967).

\section{Methodology}

\subsection{LIDAR surveys}

Airborne LIDAR (Light Detection And Ranging) surveys of the Dee estuary were carried out by the Environment Agency in 2003 and 2006, with a partial estuary survey in 2004. The 2003 and 2006 surveys have a horizontal resolution of $2 \mathrm{~m}$ and $1 \mathrm{~m}$ respectively, with vertical accuracy of $\sim 20-30 \mathrm{~cm}$. The airborne surveys were performed at low water during a spring tide to maximise the exposed estuary area. The deeper channels which retain water at low water springs were surveyed separately using boat-based swathe bathymetry (although these data are only available to the authors for 2003).

Such high resolution data sets have provided good quality bathymetric input for numerical modelling. LIDAR also provides data with which to calculate important hypsometrical properties of the estuary from which morphological behaviour can be inferred. These include:

- Cross-sectional areas

- Estuary volumes (at high water, at low water, tidal prism etc)

- Effective estuary length

- Hypsometrical profile (area/elevation relationships)

Some geometrical properties have been calculated and interpreted below.

\subsection{Numerical Modelling}

Numerical modelling has been applied to the Dee in order to simulate hydrodynamic tidal propagation. The hydrodynamical modelling results are then used to infer possible morphological changes. The model used is POLCOMS (Proudman Oceanographic Laboratory Coastal Ocean Modelling System) which is a 3dimensional baroclinic B-grid model. Further details of this model can be found in Holt and James (2001). Recent modifications now include volume flux calculations using a TVD scheme (Total Vartiation Diminishing, for further information on this see Sweby, 1984). TVD ensures the total depth does not become negative, which is important to retain numerical stability in cases of wetting and drying of inter-tidal areas. This therefore allows accurate hydrodynamic simulations in shallow areas such as the Dee where large areas can become immersed on each tidal cycle. This modelling has been applied to (a) realistic Dee estuary bathymetry and (b) idealised bathymetry, representing the main features in a simple way to elucidate the important controlling processes. 


\subsubsection{Realistic bathymetry}

This model uses high resolution (180m horizontally) bathymetry generated from the 2003 LIDAR survey. 24 sigma levels are used in the vertical dimension and 15 standard tidal constituents are used to force the open boundary (water elevation is specified at the seaward open boundaries and a slip condition is applied at the land boundaries). The full extent of the model domain can be seen in figures 7 and 8 . This model can be used to directly simulate hydrodynamic conditions and the nature of tidal propagation in the estuary. Modelled tidal propagation has been validated by comparing the model output with tidal observations from tide gauges in the upper estuary (Corus Jetty) and the lower estuary (Hilbre Island)(see figures $2 a$ and $2 b$ ). These are plotted to Ordnance Datum Newlyn (ODN) which is the vertical datum used for ordnance survey maps in Great Britian. It is defined as the mean sea level at Newlyn in Cornwall England, between 1915 and 1921. Results of a tidal analysis based on the simulated tidal elevations are presented with emphasis placed on localities of ebb or flood dominance and the relevance this may have to morphological behaviour.
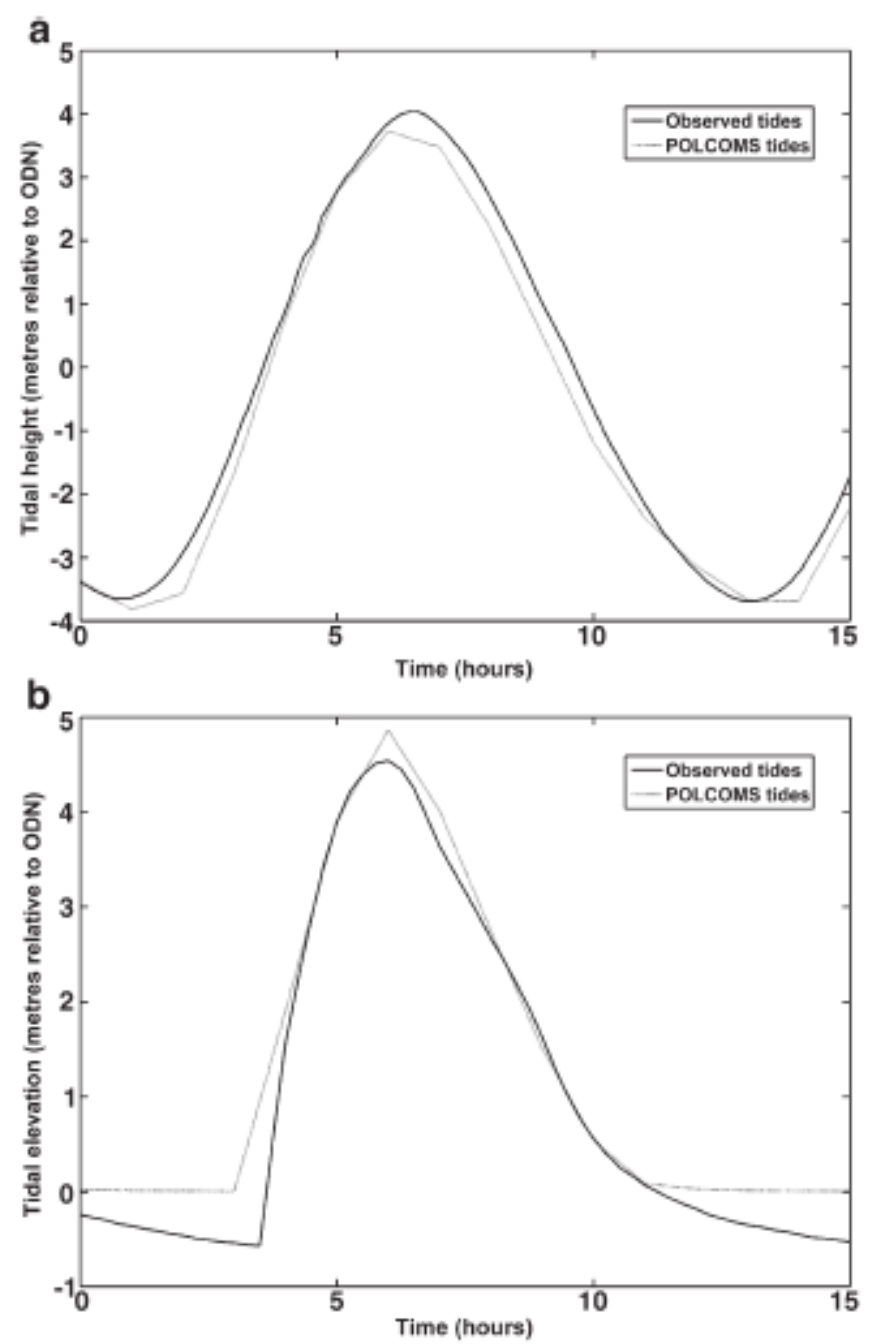

Figure 2. Tidal curves showing tide gauge observations and modelled tidal elevation. Locations are a) Hilbre Island in lower estuary near estuary mouth and b) Corus Jetty in upper estuary near canalised section. 


\subsubsection{Idealised modelling}

Idealised modelling can be a useful tool for investigating basin-wide (estuary) scale morphological behaviour. The two main concepts in idealised modelling are simplified geometry and simplified forcing. A simplified geometry will reduce the complexity of the bathymetric grid by reducing the number of cells and compartmentalising the estuary into sections, with similar depths in each section to represent mud/sand banks, saltmarshes and main tidal channel/s. Simplifying the topography in idealised models greatly reduces the computational effort required in model runs due to the reduced computational domain (number of grid-points), thereby allowing longer model runs per hour of real time. It also allows general trends in results to be easily identified. The effects of altering the depth levels of the channel/mud banks on tidal propagation are therefore easier to observe and are presented herein. It also allows artificial changes in bathymetry to be introduced to test the response of the estuary to hypothetical future morphology.

Simplifying the forcing involves reducing the number of tidal constituents applied as open boundary conditions. Here, only the principal lunar $\left(\mathrm{M}_{2}\right)$ and the principal solar $\left(\mathrm{S}_{2}\right)$ tides are applied. This tool will be used to test if morphodynamic equilibrium can be acheived by varying the bathymetry from the present day situation.

Examples of the idealised estuary bathymetric grids used can be seen in figure 9 (the relevance of these set-ups will be discussed in section 4.2.2).

\section{Results}

\subsection{Modern Dee estuary bathymetry - LIDAR surveys}

Figure 1 shows the bathymetry of the Dee using the LIDAR survey of 2003. The two main tidal channels (Hilbre channel and Mostyn channel) can be easily seen, as can the creeks and channels of the saltmarsh system of the eastern shore. Note how only the very deep parts of the channels lie below $-20 \mathrm{~m}$ ODN, with most of the estuary at an elevation above $-6 \mathrm{~m}$ ODN. It is well known that the Dee has seen large amounts of infilling and accretion over the last 2 centuries, but is this still the case? The question of whether estuaries like the Dee are in the process of achieving equilibrium or simply in the process of infilling completely is unclear, but we can investigate quantitatively the recent balance between erosion and deposition by comparing the two LIDAR surveys of 2003 and 2006. The difference between these two surveys showing the accretion and deposition occurring over those three years is shown in figure 3. It can be seen that the majority of the shallow areas of sand banks and mud banks and the saltmarshes of the eastern shore have continued to undergo accretion in recent years, although the short time between surveys make rates of accretion difficult to ascertain. Erosion is still prevalent in some regions but some of these areas may be artefacts caused by channel migration. 


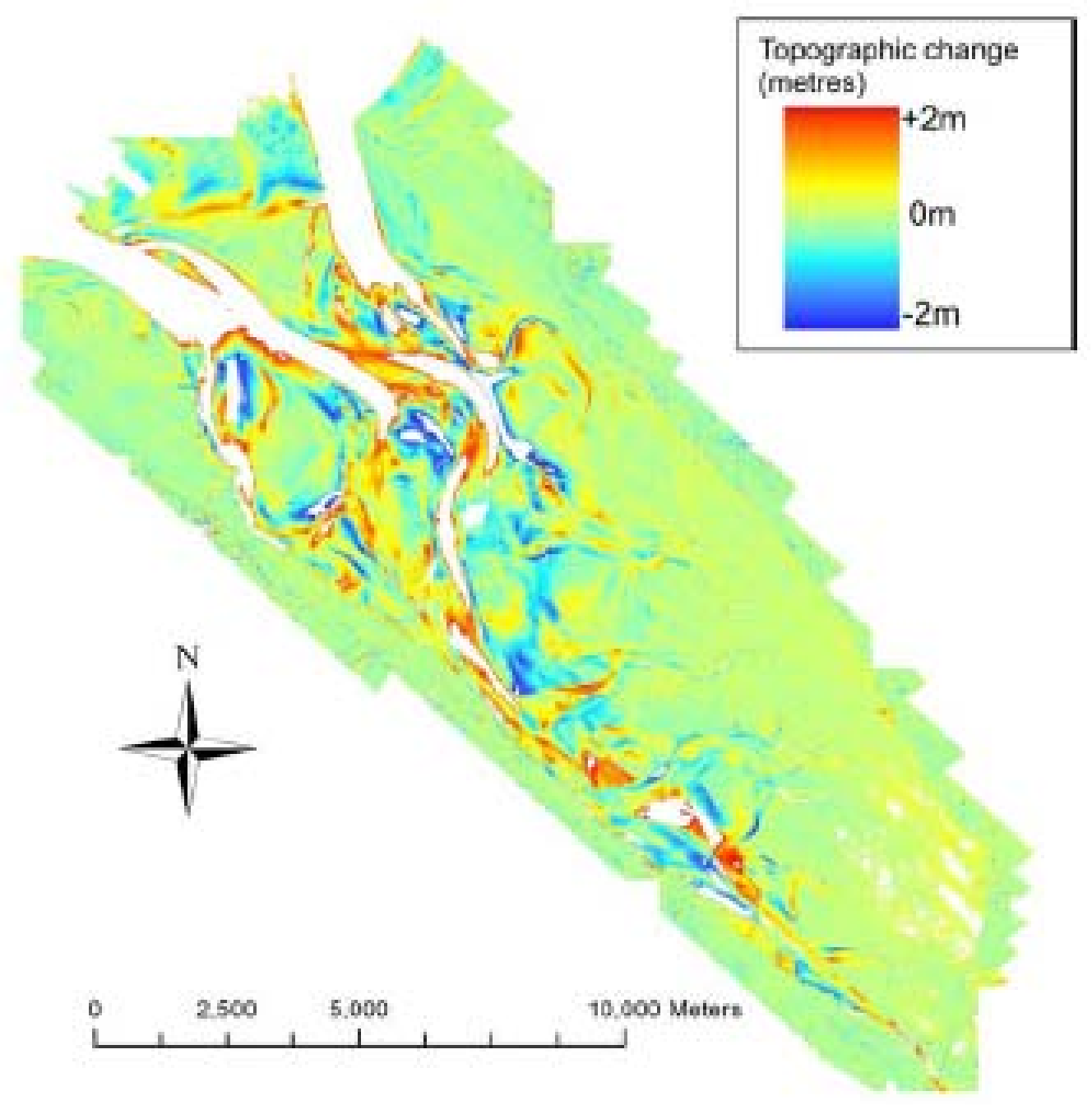

Figure 3. Bathymetric changes in the Dee estuary 2003-2006 (from LIDAR surveys).

Using the LIDAR data set, cross-sectional areas can be calculated. Several transects were selected for this purpose along the estuary. Figure 4 shows how the crosssectional area varies along estuary from the 2003 survey. Cross-sectional areas are taken relative to mean sea level. Tide-dominated estuarine are often funnel-shaped and display an exponential increase in cross-sectional area in the down-estuary direction towards the mouth (Lanzoni and Seminara, 2002). This is almost true for the Dee but with a slight linear increase along mid-estuary. 


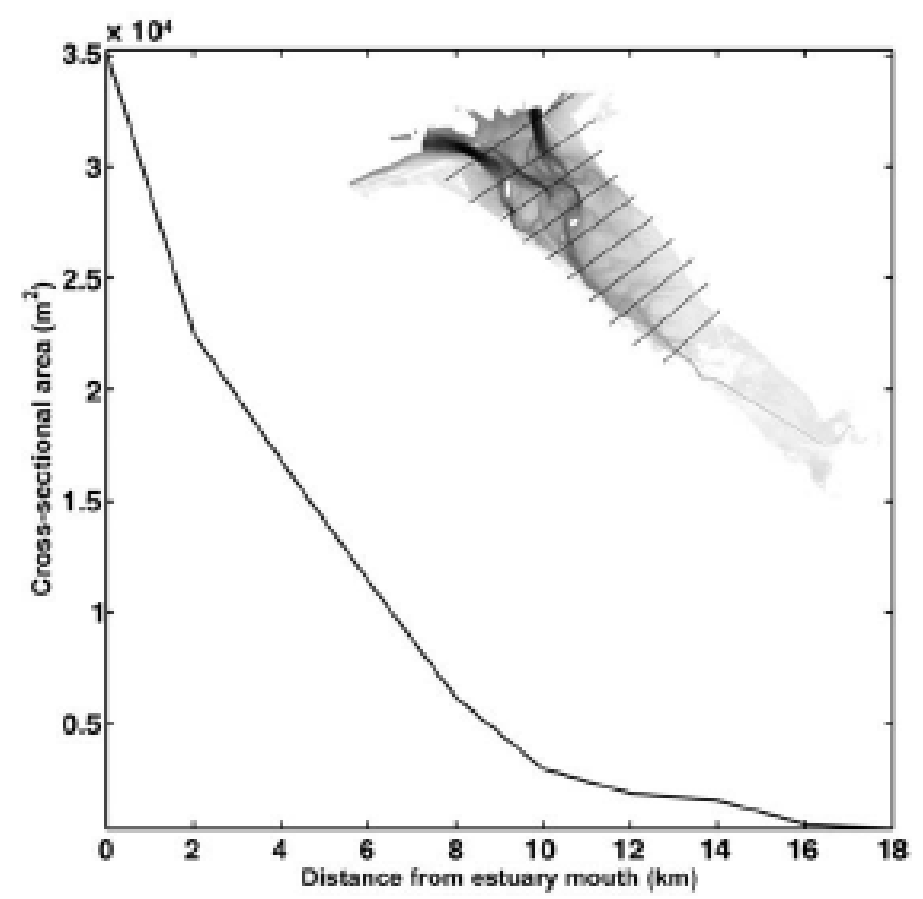

Figure 4. Up-estuary (landward) change in cross-sectional area of the Dee. Cross-sectional areas are taken relative to mean sea level.

Estuarine hypsometry refers to the distribution of basin surface area to elevation and has been suggested as a controlling factor of the vertical tidal propagation (Boon and Byrne, 1981). Several studies have investigated the application of empirical formulae to hypsometrical relationships, following the pioneering work of Strahler (1952) (such as Boon, 1975; Boon and Byrne, 1981; Wang et al., 2002). Several approaches are discussed in detail in Townend (2008). For the purpose of this investigation, only the hypsometrical theory of Boon and Byrne (1981) will be compared to the Dee estuary hypsometry. Figure 5 shows the hypsometry curve for the Dee as generated from the 2003 LIDAR survey (non-dimensionalised basin area against non-dimensionalised basin elevation). Boon and Byrne (1981) use the hypsometry of estuaries to describe the morphology and 'maturity' (level of sediment infill) of an estuary. They derived a hypsometric curve-fitting technique to calculate dimensionless basin area shown below:

$$
\frac{a}{A}=\frac{G}{(r+G(1-r))} \quad G=\left(\frac{1-h}{H}\right)^{\gamma} \quad r=\frac{A_{\min }}{A}
$$

where $h=$ height above minimum basin elevation, $H=$ height between maximum and minimum basin elevation, $A=$ total $/$ maximum basin area, $A_{\min }=$ minimum basin area, $a=$ basin area lying below contour at height $h$, and $\gamma=$ factor controlling area below hypsometric curve (i.e. the volume of sediment in the basin). The parameter $\gamma$ can be used to describe the maturity of the estuary. An immature estuary will have $\gamma=3.5-5.0$ and be little infilled (having reasonably vertical sides) and be associated with flood dominance. Here the system may be shallow but is likely to have large inter-tidal basin storage (Wang et al., 2002). Furthermore, flood dominance is likely where bottom friction influences are important, as this contributes to overtides (higher 
harmonics), which will be further discussed in sections 4.2.1 and section 5. A more mature and sediment-filled estuary will have $\gamma=1.8-2.5$ and will have gently sloping sides, a shape they found conducive to ebb dominance. This is because a sedimentfilled estuary is likely to have a greater extent of tidal flats which are known to promote ebb dominance (e.g. Speer and Aubrey, 1985; Dronkers, 1986; Fortunato and Oliveira, 2005). This concept is also discussed further in section 5. The result from the Boon and Byrne curve-fitting technique is plotted alongside the observed LIDAR data. The $\gamma$ value for the Dee estuary was found to be 2.2. This puts the Dee into the category of a fairly mature (moderately infilled) estuary when applied to the Boon and Byrne scale. This means that the Dee estuary may be approaching a switch towards ebb dominance (following the proposal that asymmetry may favour the ebb tide when estuary infilling becomes advanced, Boon and Byrne, 1981). However, after a time a very mature, marsh-filled basin $(\gamma=1.8)$ may reach dynamic equilibrium as the channel cross-sectional area approaches its maximum value, as was found to be the case for Swash Bay, Virginia, modelled in the study site of Boon and Byrne (1981). Curves representing a hypothetical 'mature' estuary and a younger 'open' estuary are also plotted on figure 5 for comparison with the Dee hypsometry.

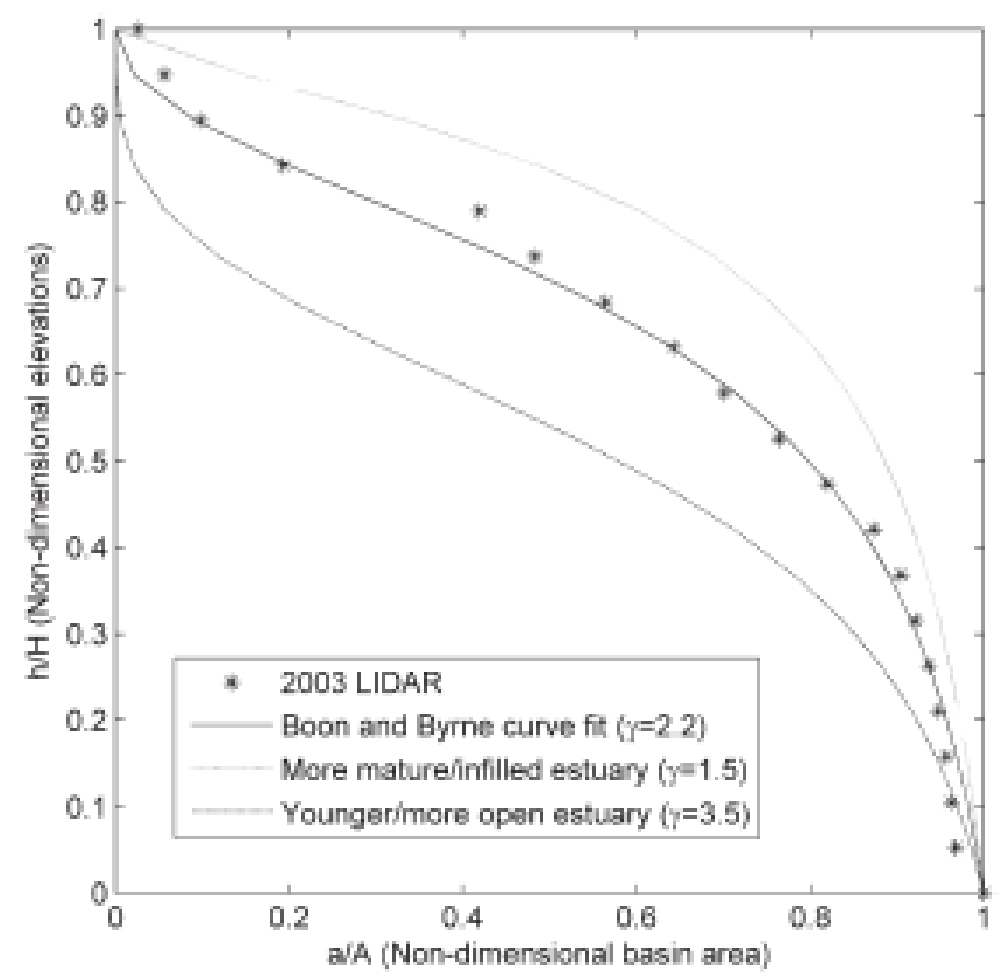

Figure 5. Hypsometry diagram (area-height relationship) showing the basin configuration of the Dee estuary. Also shown are example hypsometrical profiles of a less sediment-filled and more sediment-filled basin.

\subsection{Numerical modelling results}

\subsubsection{Realistic model bathymetry}

Tidal flow asymmetry is a result of the interactions of tidal harmonics (Fokkink et al., 1998). Utilising harmonic tidal analysis it is possible, from a time-series of tidal elevation data, to separate the individual tidal constituents. The magnitude and phase 
of the constituents present can be used to provide insights into the hydrodynamic functioning of the system (Aubrey and Speer, 1985). POLCOMS was run to generate a time-series of tidal elevation over a spring-neap cycle starting on the $12^{\text {th }}$ June 2001. The extent of the model computational grid includes a significant portion of Liverpool Bay and also the entrance to the Mersey estuary as well as the Dee (figures 7 and 8). Tidal curves were then compared against tide gauge observations in both the upper and lower estuary for validation (Figs 2a and 2b). Harmonic analysis was then applied to the elevation time-series using T-Tide analysis software (Pawlowicz et al., 2002).

Tidal asymmetry is often described as the distortion of the dominant lunar semidiurnal $\mathrm{M}_{2}$ tide by the higher frequency overtides (Wang et al., 2002). The $\mathrm{M}_{2}$ tide is the principal lunar semi-diurnal tide and is the dominant tidal constituent in Liverpool Bay. The $\mathrm{M}_{4}$ constituent is the most important harmonic overtide (Pingree and Griffiths, 1979) and is the first order harmonic overtide of the $\mathrm{M}_{2}$ constituent and it is largely generated by non-linear interactions. The non-linear transfer of energy by friction, continuity and advection enhances $\mathrm{M}_{4}$ (and other harmonic overtides), with friction in particular playing an important role in $\mathrm{M}_{4}$ generation (although advection can dominate as an $\mathrm{M}_{4}$ generation mechanism in certain geometries: Speer and Aubrey, 1985). Together with other higher order harmonics the $\mathrm{M}_{4}$ is responsible for distortion of the tidal wave. Indeed it has been found to be the main contributor to tidal distortion (asymmetry) in coastal areas (Friedrichs and Aubrey, 1988). An investigation into the spatial variability of the $\mathrm{M}_{4}$ tide in the Irish Sea is presented in Davies and Lawrence (1994). A comparison between the $\mathrm{M}_{4}$ constituent and the $\mathrm{M}_{2}$ constituent can be used as an indicator of the degree of tidal distortion and asymmetry present. The amplitudes of these two constituents in the Dee (as found from the harmonic analysis) are shown in figures $6 \mathrm{a}$ and $6 \mathrm{~b}$.
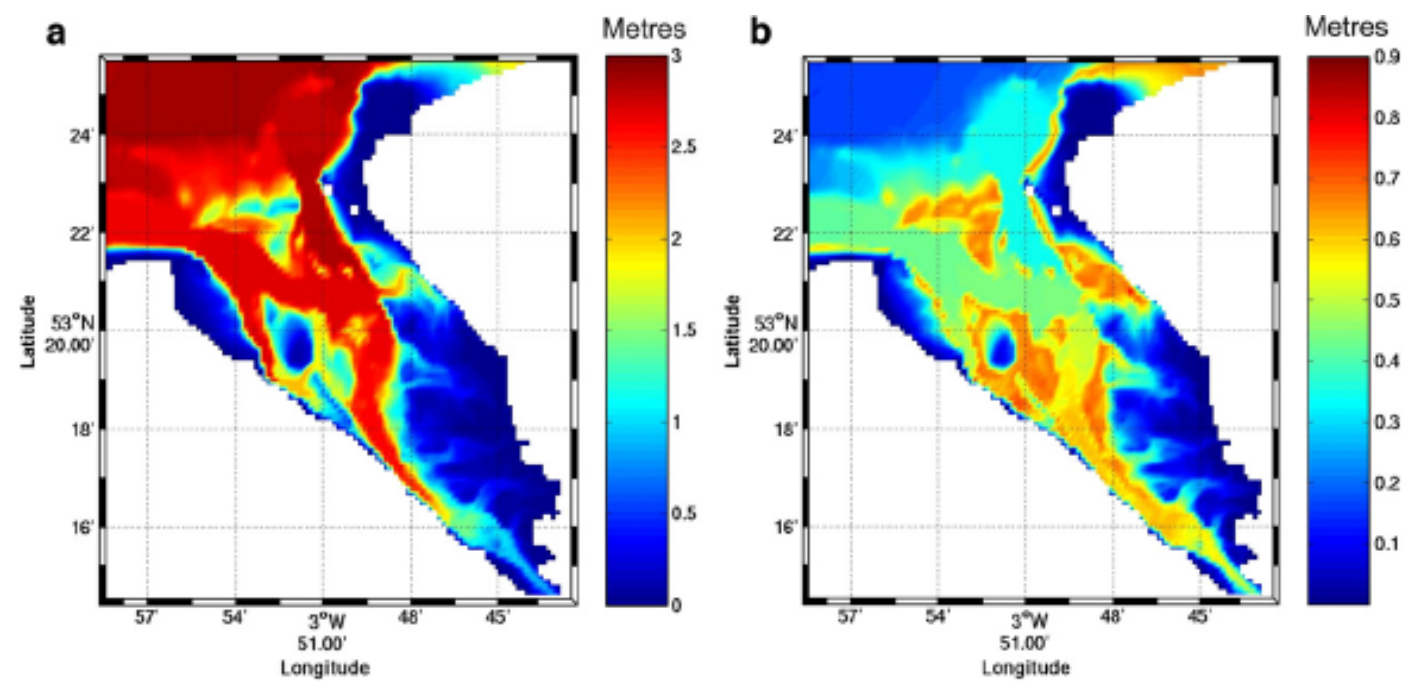

Figure 6. Tidal constituent amplitudes in the Dee estuary : a) $M_{2}$ amplitude b) $M_{4}$ amplitude

Friedrichs and Aubrey (1988) propose the following 2 equations for describing the tide:

Tidal distortion factor (uses constituent amplitudes): 
$\mathbf{M}_{4 \mathbf{a m p}} / \mathbf{M}_{\mathbf{2 a m p}}>0.01$ indicates significant distortion of the tidal wave

Tidal dominance factor (uses constituent phases):

$\mathbf{2 M}_{\mathbf{2 \theta}}-\mathbf{M}_{\mathbf{4 \theta}}: 0^{\circ}-180^{\circ}=$ flood dominant; $180^{\circ}-360^{\circ}=$ ebb dominant.

Subscripts amp and $\boldsymbol{\theta}$ designate constituent amplitude and phase respectively.

These parameters for tidal distortion and asymmetry in the Dee and Liverpool Bay are shown in figures 7 and 8 . Figure 7 shows that the tide outside the estuary is relatively undistorted and symmetrical but becomes highly distorted on entering the Dee, particularly on reaching the shallowest regions. The highly distorted tidal areas coincide with the areas of high $\mathrm{M}_{4}$ amplitude (figure $6 \mathrm{~b}$ ), as expected. A large distortion factor reflects both shallow water frictional energy dissipation (reduced $\mathrm{M}_{2}$ amplitude) and non-linear energy transfer from $\mathrm{M}_{2}$ to $\mathrm{M}_{4}$ (Aubrey and Speer, 1985). Figure 8 indicates tidal asymmetry by phase differences and shows that these same shallow, highly tidally distorted regions tend to be flood-dominated (phase difference $<180^{\circ}$ ). This would explain the accreting nature of these areas of the estuary as the likelihood of a flood dominant region importing sediment has already been discussed, with reference to the literature.

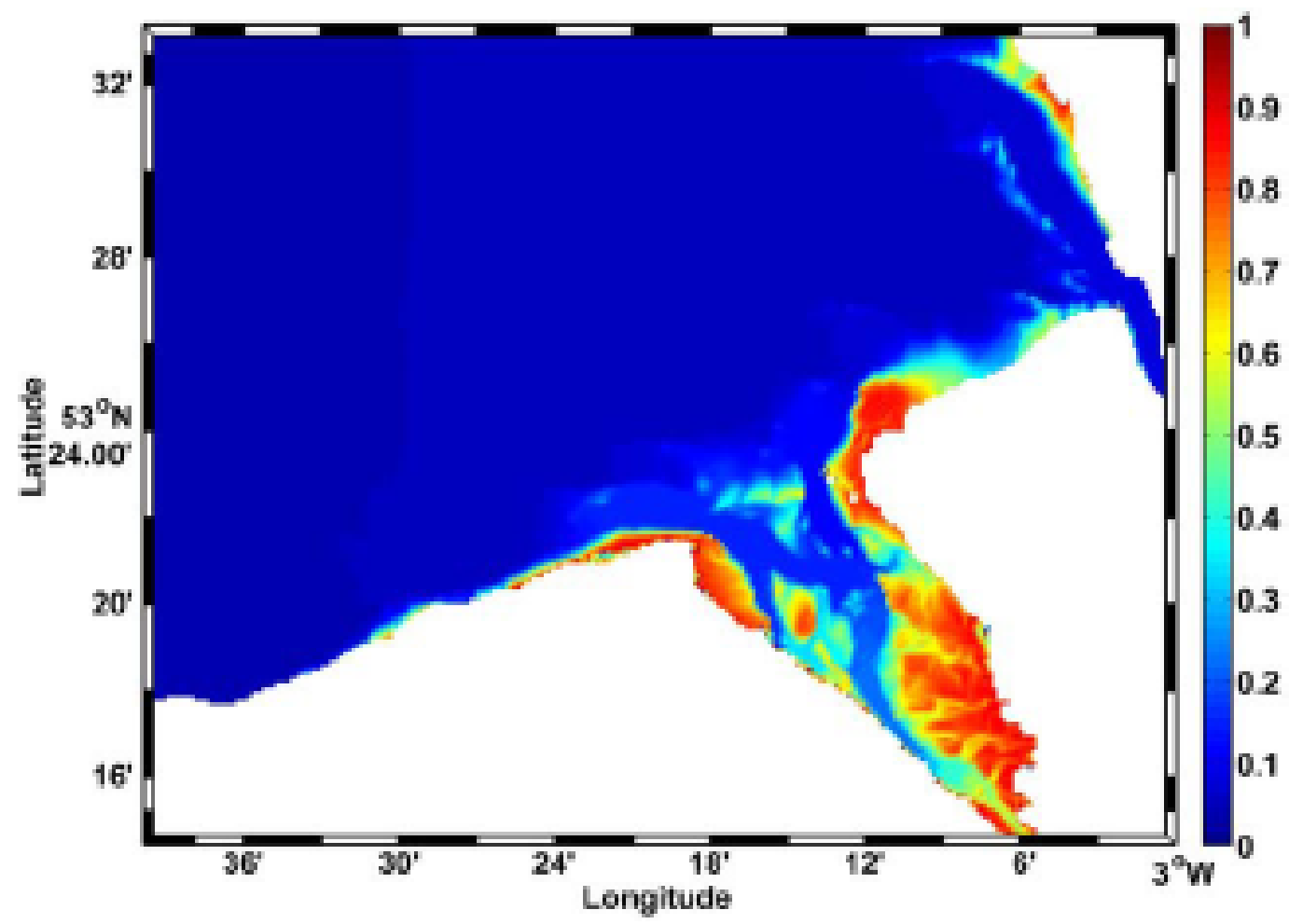

Figure 7. $\mathbf{M}_{4 a m p} / \mathbf{M}_{2 a m p}$ as an indicator of tidal distortion (criteria from Friedrichs and Aubrey, 1988) 


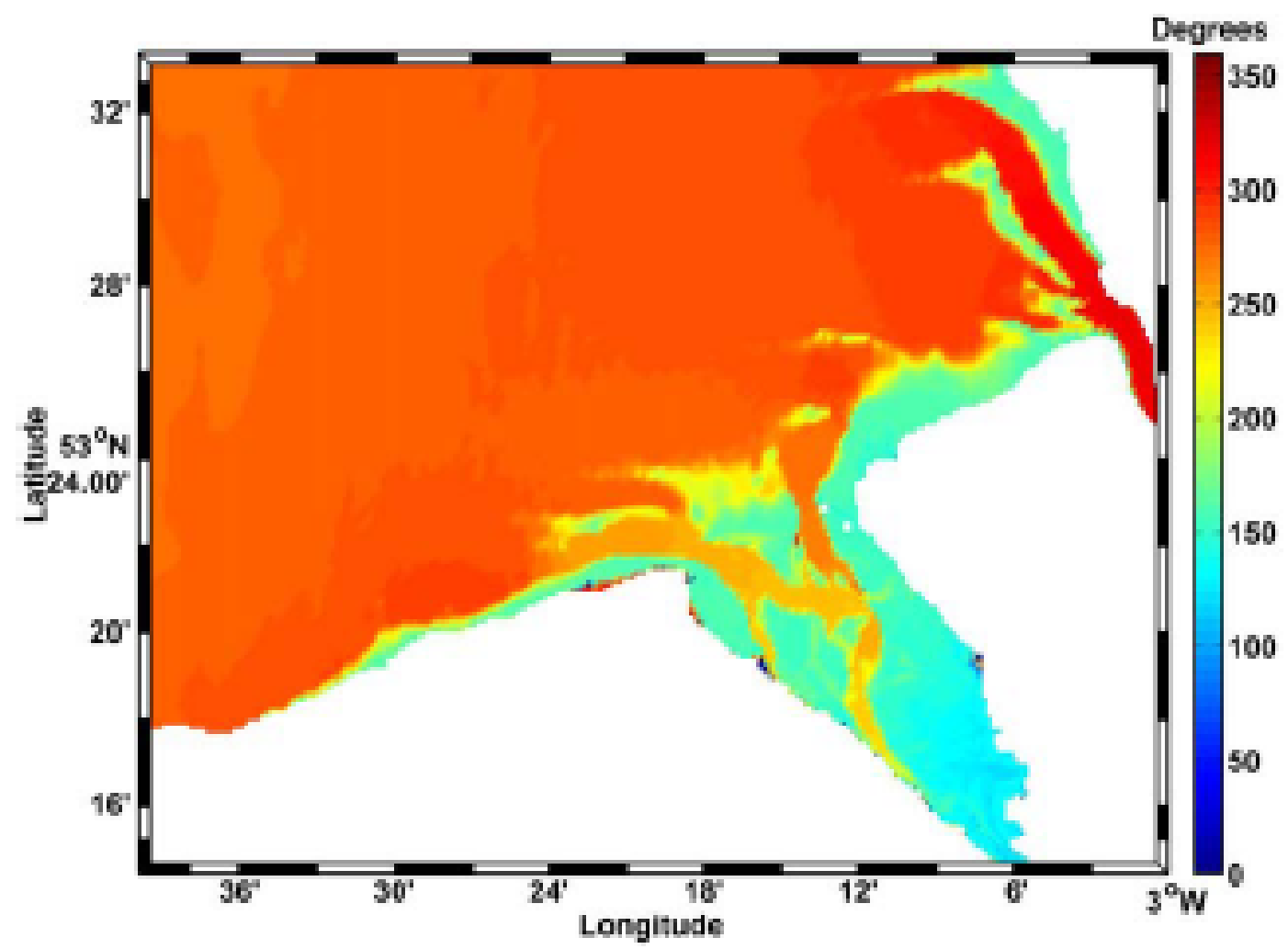

Figure 8. $2 \mathrm{M}_{2 \theta}-\mathrm{M}_{4 \theta}$ as an indicator of tidal dominance in degrees (criteria of Friedrichs and Aubrey, 1988)

In contrast, the two main tidal channels appear to be ebb dominant. However, the level of tidal distortion throughout the channels is much lower than that of the shallow mud and sand banks (the channels are therefore only weakly ebb dominant).

\subsubsection{Idealised estuary modelling}

Idealised modelling has proved to be a useful tool in numerical modelling. Simplifications to the bathymetry and external forcing mean less computational effort is required and can make physical relations and trends easier to identify. In this study simple triangular (funnel-shaped) estuarine bathymetries were used in the numerical model POLCOMS. In the first test case depths were chosen so as to be representative of depths in the Dee estuary today. Two further test cases used shallower bathymetry to simulate the effects of accretion. This was applied to the sand and mud banks at the edges of the estuary (plus $2 \mathrm{~m}$ and plus $4 \mathrm{~m}$ accretion respectively). These 3 bathymetric grids are shown in figure 9 , called test $\mathrm{a}, \mathrm{b}$ and $\mathrm{c}$ respectively. Deposition on the banks was combined with some erosion of the main channels, as often bank accretion is a result of sediment redistribution within the estuary, rather than solely by net sediment import. For example, the tidal wave propagates faster in the channels than on the tidal flats (Dronkers, 1986) so there may be a degree of sediment transfer between the two regions. The external tidal forcing at the open boundaries for all three test cases was reduced to just the $\mathrm{M}_{2}$ and $\mathrm{S}_{2}$ tidal constituents (principal lunar and principal solar constituents respectively). 

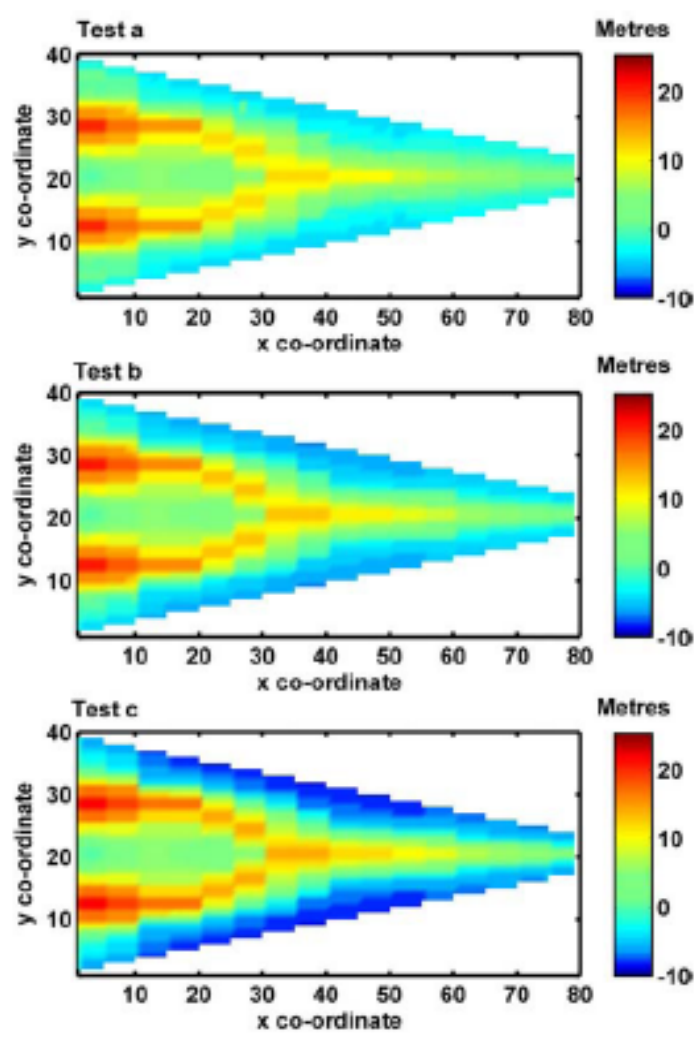

Figure 9. Example of a bathymetric grid used to represent a simple funnel-shaped 'idealised' estuary (depths given are in metres)

The hydrodynamic results were then harmonically analysed to investigate what effect increasing the sand and mud bank elevation would have on the flood and ebb dominance within the estuary, using the phase difference parameter. For the three test cases, the ebb/flood dominance parameter has been cross-sectionally averaged and plotted along the estuary in figure 10. For all three cases, the tidal propagation appears to be more flood dominant further up-estuary.

Some interesting changes are seen between the three test cases. Figure 10 shows that increasing the elevation of the sand and mud banks tends to increase the level of ebb dominance (i.e. leads to an increase of the phase difference parameter). This is because large areas of high tidal flats have been found to increase the maximum current on the ebb flow (Speer and Aubrey, 1985; Dronkers, 1986). This trend generally persists for the full length of the estuary, but more so in the upper estuary where the inter-tidal area is greatest. 


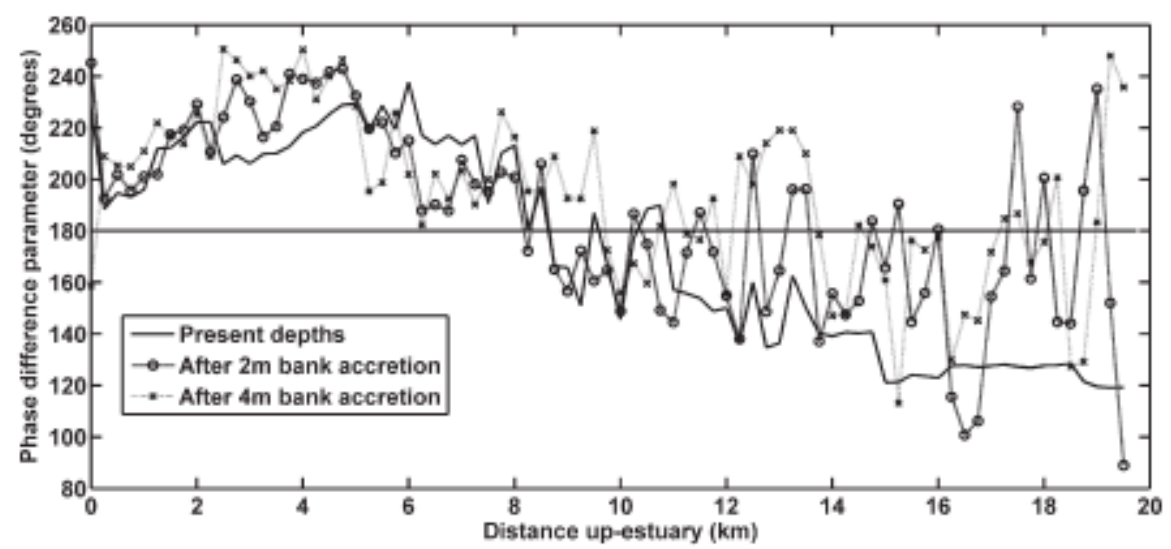

Figure 10. Up-estuary changes in tidal asymmetry parameter to show ebb/flood dominance in idealised estuary model tests

\section{Discussion}

Separating the tidal signal into its various constituents can give valuable insight into the hydrodynamical processes. Figures $6 \mathrm{a}$ and $6 \mathrm{~b}$ show the amplitude of the $\mathrm{M}_{2}$ and $\mathrm{M}_{4}$ constituents. $\mathrm{M}_{2}$ decays in amplitude as it propagates up the estuary. This is due to both frictional dissipation and the non-linear transfer of energy to higher harmonics (Aubrey and Speer, 1985). Bottom friction opposes tidal current flow and increases as the square of the current speed, acting to dissipate and reduce the energy in the tidal motion (Pugh, 2004). In contrast to $\mathrm{M}_{2}$, its higher harmonic, $\mathrm{M}_{4}$, has regions of high amplitude within the estuary, compared to being almost negligible in Liverpool Bay.

We have shown in figures 7 and 8 how the $\mathrm{M}_{2}$ and $\mathrm{M}_{4}$ tidal constituents can be used to estimate the level of tidal distortion and asymmetry (as in Friedrichs and Aubrey, 1988). The magnitude and phase of these two constituents can be calculated spatially and temporally, given a sufficiently long time-series of tidal elevation. The nature of tidal propagation (i.e. distortion, asymmetry) can be used to explain previous morphological changes and thus to infer future changes (flood dominance is likely to import sediment and ebb-dominance will likely export sediment).

The shallow areas of the Dee are the mudbanks, sandbanks and saltmarshes and are the most tidally distorted regions of the estuary (figure 7). The asymmetry of these tidally distorted areas is highly flood-dominant (figure 8). This is in agreement with previous studies which have found shallower regions to show greater flood dominance than deeper areas (Wang et al., 2002). This is emphasised by figure 11, which is a scatter plot of the numerical model grid points showing that flood dominated areas tend to be shallower than 2m below MSL (Mean Sea Level), while ebb dominant areas are generally deeper than this elevation. The shallow flood dominant areas correspond to regions where bottom friction has a large effect (causing a reduction in $\mathrm{M}_{2}$ amplitude) and where shallow water distortion occurs (increases the $\mathrm{M}_{4}$ amplitude). The main channels are actually ebb dominant, but weakly so (the tide is relatively undistorted), but this may be a sufficient mechanism by which the deep conveyance channels remain open. 


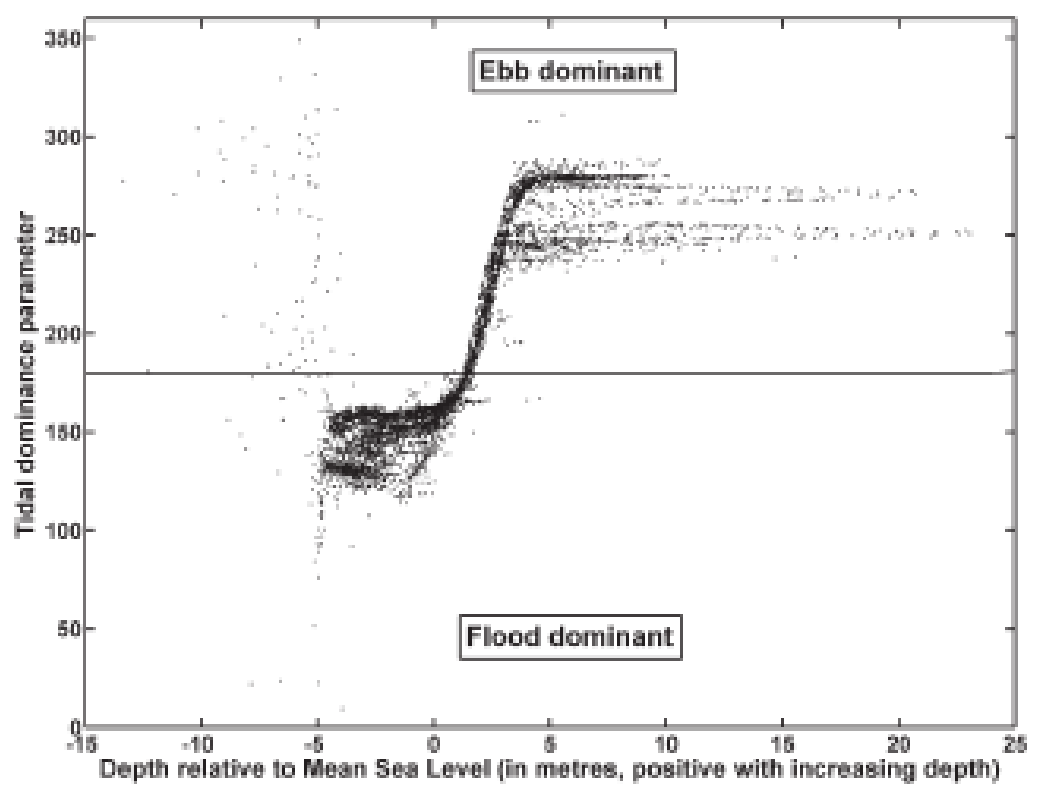

Figure 11. Tidal dominance parameter plotted against estuarine depth

Using the $\mathrm{M}_{2}$ and $\mathrm{M}_{4}$ phase difference technique, Townend (2005) found the majority of UK estuaries to be flood dominant. However, when tested using estuary form analysis methods (see Dronkers, 1998) Townend found that most appeared to be ebb dominant, a conflict possibly due to the large diversity of estuaries found in the UK. Townend attributed flood dominance to very high ratios of the tidal amplitude $(a)$ to the hydraulic depth of the estuaries $(h)$. When $a / h$ is large the tide wave crest (high water) travels more quickly than the trough (low water) due to the greater depth beneath the crest, hence, shortening the flood duration (Friedrichs and Aubrey, 1988).

When the majority of an estuary is flood dominant (as we have shown the Dee to be in figures 7 and 8) this implies net landward movement of sediment, resulting in a trend towards estuarine infill. A detailed explanation of flood dominance leading to sediment trapping in macrotidal estuaries is given in Castaing and Allen (1981). This concept is broadly in agreement with the LIDAR data. It has been suggested that an estuary will have a tendency towards flood dominance until basin sediment-infilling becomes advanced, which may then lead to ebb dominance (Boon and Byrne, 1981). At some point the estuary may therefore switch towards ebb dominance and act as a sediment source rather than a sediment sink. The estuary may reach a certain stage where it finds morphological equilibrium (the morphology compliments the hydrodynamics such that there is zero net sediment flux). The hypsometry of the Dee depicts a fairly 'mature' estuary which has undergone substantial infilling and, therefore, suggests it may be approaching equilibrium or a switch towards ebb dominance and that the rate of sedimentation may decrease in the future.

A switch towards ebb dominance has been strongly linked with tidal flat formation (Speer and Aubrey, 1985; Dronkers, 1986; Kang and Jun, 2003; Fortunato and Oliveira, 2005). Fortunato and Oliviera (2005) found that large tidal flats increase the ebb dominance provided they are exposed at low water, and that tidal flats distributed at an elevation of mean water level or slightly above maximise this potential. Dronkers (1986) states that the effect of wind waves on tidal flats (initially formed by tidal currents) may eventually result in an export of sediment. This is because advanced tidal flats will only be inundated at high water, therefore sediment 
resuspension by wave action on the flats will also occur at high water, which means higher suspended sediment concentrations and suspended sediment transport during the ebb flow. Also, the available fetch is greatest at high water, meaning that incident waves will have maximum effect at this time (Le Hir et al., 2000). The tidal asymmetry can also be affected by the topography of the intertidal flats, as a convex cross-shore profile has been found to increase ebb dominance (e.g. Le Hir et al., 2000). Hence, at some stage in an infilling estuary, the area and extent of the tidal flats (sand and mud banks) may become sufficient to 'overpower' the flood dominance. Speer and Aubrey (1985) state the difficulties in assessing the area of tidal flats needed for a flood to ebb transition to occur. For example, low values of $\mathrm{a} / \mathrm{h}$ and weaker values of friction may mean less extensive tidal flats are necessary to induce ebb dominance (Speer and Aubrey, 1985). Since high tidal amplitudes enhance flood dominance (Fortunato and Oliviera, 2005), the large tidal ranges found in the Dee may mean that tidal flat areas would have to be very extensive for a switch towards ebb dominance. At present, tidal flats occupy around $55 \%$ of the estuary by area, with deeper channel areas comprising roughly $45 \%$ (these values do not include salt marsh areas).

The results seen in our idealised estuary modelling agree with the above theory which suggest that increasing the elevation and extent of the sand and mud banks (tidal flats) at the edge of the estuary increases the tendency for ebb dominance. In this way a flood dominant estuary acting as a sediment sink may eventually switch to ebb dominance and act instead as a sediment source. Thus the estuarine shape is selflimiting. The recent rapid infilling of the Dee may be due to readjustment to the relatively recent canalisation and reclamation i.e. man's intervention. The time-scale over which the switch to ebb-dominance occurs is probably unique to each estuary. Factors such as climate and sediment supply and anthropogenic effects may also be important in this determination. Very shallow estuaries, however, tend to maintain flood dominance unless the area of intertidal flats becomes very extensive (Speer and Aubrey, 1985).

Although a switch towards ebb dominance is possible with sufficient infilling, it may be a transitory phenomenon, as it is known that estuaries do fill in entirely and become extinct. Indeed over a geological time-scale estuaries are seen as very ephemeral entities (Lanzoni and Seminara, 2002). Coastal plain estuaries in particular (consisting of unconsolidated rock) have changed considerably in the last 3000 years of approximate sea level still-stand, with vast areas of sand and mud banks building up to high tide level and becoming occupied with grassy marshes (Russell, 1967). Such is the case in the Dee today, following the high sedimentation and widespread colonisation of saltmarsh which is known to have taken place over the last 2 centuries (as described in section 2). Russell (1967) describes deltas as being the greatest natural threat to estuaries, suggesting that in a few thousand years estuaries could be very rare, sedimentary infilling having replaced them with alluvial flood plains which widen seawards and deltaic coastlines. So, rather than estuaries finding a long-term morphological equilibrium, periods of ebb-dominance (and sediment flushing) may punctuate a long-term trend of flood dominance and sedimentary infilling. 


\section{Conclusions}

Morphological changes can have important implications for coastal environments, especially in estuaries which tend to be areas of high commercial, recreational and ecological interest. This study has attempted to explain the recent morphological behaviour and current morphological status of the macrotidal Dee estuary, UK. To do so this investigation has used numerical modelling of hydrodynamics to assess the nature of the tidal propagation, and has used analysis of LIDAR surveys as a means of ascertaining recent bathymetric changes and basin configuration.

This study has found that, in a macrotidal system, such as the Dee, much of the morphological behaviour can be explained by comparing the $\mathrm{M}_{2}$ and $\mathrm{M}_{4}$ tidal constituents in the tidal signal, as tidal asymmetry is a major forcing factor of morphological change. Through this method a substantial area of the estuary was found to be very tidally distorted and generally flood dominant. This is suggestive of net sediment import into the estuary, an interpretation that is independently supported by high resolution LIDAR surveys of the Dee, which show predominantly net accretion between 2003 and 2006. The hypsometrical analysis, however, suggests that the Dee may be approaching morphological equilibrium ('maturity') and that the rate of accretion may therefore decrease in the future. However it is imperative that other physical factors are considered. For example, over the geological time-scale sediment supply may ultimately exceed the available accommodation space leading to complete basin-infilling. Conversely increased storminess and relative sea level rise may increase coastal erosion rates leading to the 'drowning' of the estuary. In these instances equilibrium may not be achieved at all. Also if the physical conditions are in a constant state of flux the estuary may be continuously adapting to reach a static morphology which it never attains, a kind of transient or quasi-equilibrium state.

\section{Acknowledgments}

The LIDAR data surveys were collected by the Environment Agency (EA) for the Tidal Dee User Group Consortium (TDUG) including Proudman Oceanographic Laboratory. This research has been funded by a Natural Environment Research Council studentship (NERC) with CASE industry sponsorship from Airbus UK.

\section{References}

Aubrey, D.G., Speer, P.E., 1985. A study of non-linear tidal propagation in shallow inlet/estuarine systems, part 1: observations. Estuarine, Coastal and Shelf Science 21, 185-205.

Boon, J, D. 1975. Tidal discharge asymmetry in a salt marsh drainage system. Limnology and Oceanography, 20, 71-80.

Boon, J.D, Byrne, R.J., 1981. On basin hypsometry and the morphodynamic response of coastal inlet system. Marine Geology 40, 27-48.

Castaing, P., Allen, G.P., 1981. Mechanisms controlling seaward escape of suspended sediments from the Gironde: a macrotidal estuary in France. Marine Geology 40, 101-118. 
Davies, A.M., Lawrence, J., 1994. A three-dimensional model of the M4 tide in the Irish Sea: the importance of open boundary conditions and influence of wind. Journal of Geophysical Research 99 (C8), 16197-16227.

Dronkers, J., 1986. Tidal asymmetry and estuarine morphology. Netherlands Journal of Sea Research 20, 117-131.

Dronkers, J., 1998. Morphodynamics of the Dutch delta. In: Dronkers J, Scheffers MBAM (Eds.), Physics of Estuaries and Coastal Seas, Balkema, Rotterdam, pp. 297304.

Fokkink, R.J., Karssen, B., Wang, Z.B., 1998. Morphological modelling of the Western Scheldt estuary. In: Dronkers J, Scheffers MBAM (Eds.), Physics of Estuaries and Coastal Seas, Balkema, Rotterdam, pp. 329-337.

Fortunato, A.B., Oliveira, A. 2005. Influence of intertidal flats on tidal asymmetry. Jounral of Coastal Research 21, 1062-1067.

Friedrichs, C.T., Aubrey, D.G., 1988. Non-linear tidal distortion in shallow wellmixed estuaries: a synthesis. Estuarine, Coastal and Shelf Science 27(5), 521-546.

Friedrichs, C.T., Madsen, O.S. 1992. Nonlinear diffusion of the tidal sugnal in frictionally dominated estuaries. Journal of Geophysical Research 97, 5637-5650.

Holt, J.T., James, I.D. 2001. An s coordinate density elolving model of the northwest European continental shelf. Jounral of Geophysical Research 106, 14015-14034.

Hume, T.M., Herdendorf, C.E., 1993. On the use of empirical stability relationships for characterising estuaries. Journal of Coastal Research 9(2), 413-422.

Hutchinson, S.M. and Prandle, D., 1994. Siltation in the saltmarsh of the Dee estuary derived from 137Cs analysis of shallow cores. Estuarine, Coastal and Shelf Science 38, 471-478.

Kang, J.W., Jun, K.S. 2003. Flood and ebb dominance in estuaries in Korea. Estuarine, Coastal and Shelf Science 56, 187-196.

Lanzoni, S., Seminara, G., 2002. Long-term evolution and morphodynamic equilibrium of tidal channels. Journal of Geophysical Research 107 (C1).

Le Hir, P., Roberts, W., Cazaillet, O., Christie, M., Bassoullet, P., Bacher, C. 2000. Characterisation of intertidal flat hydrodynamics. Continental Shelf Research 20, 1433-1459.

Lesser, G.R., Roelvink, J.A., Van Kester, J.A.T.M., Stelling, G.S., 2004. Development and validation of a three-dimensional morphological model. Coastal Engineering 51, 883-915.

Marker, M.E., 1967. The Dee Estuary - its progressive silting and salt marsh development. Transactions of the Institute of British Geographers 41, 65-71.

Nicholson, J., Broker, I., Roelvink, J.A., Price, D., Tanguy, J.M., Moreno, L., 1997. Intercomparison of coastal area morphodynamic models. Coastal Engineering 31, 97 123.

Pawlowicz, R., Beardsley, B., Lentz, S., 2002. Classical tidal harmonic analysis including error estimates in MATLAB using T-TIDE. Computers and Geosciences 28, 929-937.

Pingree, R.D., Griffiths, D.K., 1979. Sand transport paths around the British Isles resulting from M2 and M4 tidal interactions. Journal of the Marine Biological Association UK 59, 497-513.

Prandle, D., 2004. Sediment trapping, turbidity maxima, and bathymetric stability in macro-tidal estuaries. Journal of Geophysical Research 109 (C8), C08001.

Prandle, D., Lane, A., Manning, A.J., 2006. New typologies for estuarine morphology. Geomorphology 81, 309-315.

Pugh, D., 2004. Changing Sea Levels. Cambridge University Press. 
Russell, R.J., 1967. Origins of estuaries. In: Lauff, G.H. (Eds.), Estuaries. American Association for the Advancement of Science, Washington D.C., pp. 93-99.

Speer, P.E., Aubrey, D.G., 1985. A study of non-linear tidal propagation in shallow inlet/estuarine systems, part II: theory. Estuarine, Coastal and Shelf Science 21, 207224.

Strahler, A.N, 1952. Hypsometric (area-altitude) analysis of erosional topography. Geol. Soc. Am. Bull. 63: 1117-1142.

Sweby, P.K. 1984. High resolution schemes using flux limiters for hyperbolic conservation laws. SIAM Journal of Numerical Analysis 21, 995-1011.

Townend, I., 2005. An examination of empirical stability relationships for UK estuaries. Journal of Coastal Research 21, 1042-1053.

Townend, I. 2008. Hypsometry of estuaries, creeks and breached sea wall sites. Proceedings of the Institution of Civil Engineers, Maritime Engineering. 161, 23-32.

Van Dongeren, A.R., De Vriend, H.J., 1994. A model of morphological behaviour of tidal basins. Coastal Engineering 22, 287-310.

Wang, Z.B., Louters, T. and De Vriend, H.J., 1995. Morphodynamic modelling for a tidal inlet in the Wadden Sea. Marine Geology 126, 289-300.

Wang, Z.B., Jeuken, M.C.J.L., Gerritsen, H., De Vriend, H.J., Kornman, B.A., 2002. Morphology and asymmetry of the vertical tide in the Westerschelde estuary. Continental Shelf Research, 22, 2599-2609. 